\title{
Klaus Geppert
}

Der Grundsatz der Unmittelbarkeit im deutschen Strafverfahren 

Klaus Geppert

\section{Der Grundsatz der Unmittelbarkeit im deutschen Strafverfahren}

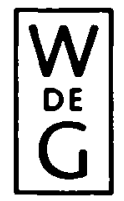

1979

Walter de Gruyter · Berlin · New York 


\section{Dr. jur. Klaus Geppert}

o. Professor an der Freien Universität Berlin

CIP-Kurztitelaufnabme der Deutschen Bibliothek

Geppert, Klaus:

Der Grundsatz der Unmittelbarkeit im deutschen Strafverfahren / Klaus Geppert. - Berlin, New York : de Gruyter, 1979.

ISBN 3-11-007256-4

Als Habilitationsschrift

auf Empfehlung der Rechtswissenschaftlichen Fakultät der Albert-Ludwigs-Universität Freiburg im Breisgau gedruckt mit Unterstützung der Deutschen Forschungsgemeinschaft

\footnotetext{
(c)

Copyright 1978 by Walter de Gruyter \& Co., vormals G. J. Göschen'sche Verlagshandlung, J. Guttentag, Verlagsbuchhandlung, Georg Reimer, Karl J. Trübner, Veit \& Comp., 1000 Berlin 30

Alle Rechte, insbesondere das Recht der Vervielfältigung und Verbreitung sowie der Ubersetzung, vorbehalten. Kein Teil des Werkes darf in irgendeiner Form (durch Fotokopie, Mikrofilm oder ein anderes Verfahren) ohne schriftliche Genehmigung des Verlages oder unter Verwendung elektronischer Systeme verarbeitet, vervielfältigt oder verbreitet werden.

Printed in Germany
}

Satz und Druck: Saladruck, Steinkopf \& Sohn, 1000 Berlin 36

Buchbinderei: Wübben \& Co., 1000 Berlin 42 
Meinem verehrten Lehrer

Rudolf Schmitt 
